\section{JTI}

JOURNAL OF

TRAUMA AND INJURY

\title{
A Carbon Monoxide Poisoning Case in Which Hyperbaric Oxygen Thera- py Was Not Possible Due to Iatrogen- ic Pneumothorax after Unnecessary Central Catheterization
}

\author{
Hyung Il Kim, M.D., Seong Beom Oh, M.D. \\ Department of Emergency Medicine, Dankook University Hospital, College of Medicine, \\ Dankook University, Cheonan, Korea
}

Accepted: December 13, 2019

\section{Correspondence to}

Seong Beom Oh, M.D.

Department of Emergency Medicine, Dankook University Hospital, College of

Medicine, Dankook University,

201 Manghyang-ro Dongnamgu,

Cheonan 31116, Korea

Tel: +82-41-550-6840

Fax: +82-41-556-0524

E-mail: holytiger@hanmail.net
Hyperbaric oxygen therapy (HBOT) is used to treat carbon monoxide (CO) poisoning. However, untreated pneumothorax is an absolute contraindication for HBOT. More caution is needed with regard to monoplace hyperbaric chambers, as patient monitoring and life-saving procedures are impossible inside these chambers. Central catheterization is frequently used for various conditions, but unnecessary catheterization must be avoided because of the risk of infection and mechanical complications. Herein, we describe a case of CO poisoning in which iatrogenic pneumothorax developed after unnecessary subclavian central catheterization. The patient did not need to be catheterized, and HBOT could not be performed because of the pneumothorax. Hence, this case reminds us of basic — but nonetheless important—principles of catheterization.

Keywords: Hyperbaric oxygenation; Complications; Pneumothorax; Catheterization, Central venous

\section{INTRODUCTION}

The basic principle of hyperbaric oxygen therapy (HBOT) is to provide patients with pure oxygen at a pressure that exceeds atmospheric pressure. HBOT has various clinical applications, including carbon monoxide $(\mathrm{CO})$ poisoning, air embolism, wound healing, decompression sickness, and radiation injury. Traditionally, the most common therapeutic use of HBOT in Korea has been to treat CO poisoning. However, 
untreated pneumothorax is a contraindication for HBOT. Particular caution is needed with regard to monoplace hyperbaric chambers because it is not possible to monitor patients inside these chambers, which medical personnel cannot enter.

Central catheterization is frequently used when caring for critically ill patients as a way to infuse vasopressors, monitor central venous pressure, and obtain emergency vascular access. However, unnecessary catheterization must be avoided because catheter-induced infections and mechanical complications can develop.

We experienced a case in which iatrogenic pneumothorax after unnecessary subclavian central catheterization prohibited a patient from being treated with HBOT. Therefore, this case reminds us of the basic principles of catheterization.

\section{CASE REPORT}

A 28-year-old woman was transferred to the emergency department (ED) of a local hospital with depressed mental status. She had no previous medical history and had lived by herself in a small efficiency apartment. She was discovered in her bathroom with a burnt charcoal briquette. Non-contrast brain computed tomography (CT) and brain diffusion magnetic resonance imaging (MRI) were performed at the local ED. She was transferred to our ED for HBOT. She was comatose, with a Glasgow coma scale (GCS) score of 8 (E4V2M2). Her blood pressure was $110 / 67 \mathrm{mmHg}$, her heart rate was 100/min, her respiratory rate was 16 breaths/min, and her body temperature was $36.9^{\circ} \mathrm{C}$. Her pupils were $5 \mathrm{~mm}$ in size and symmetrical. A grade 3 pressure sore measuring $5 \times 8 \mathrm{~cm}$ was noted on her right buttock (Fig. 1). The initial $\mathrm{PaO}_{2}$ was $104 \mathrm{mmHg}$,
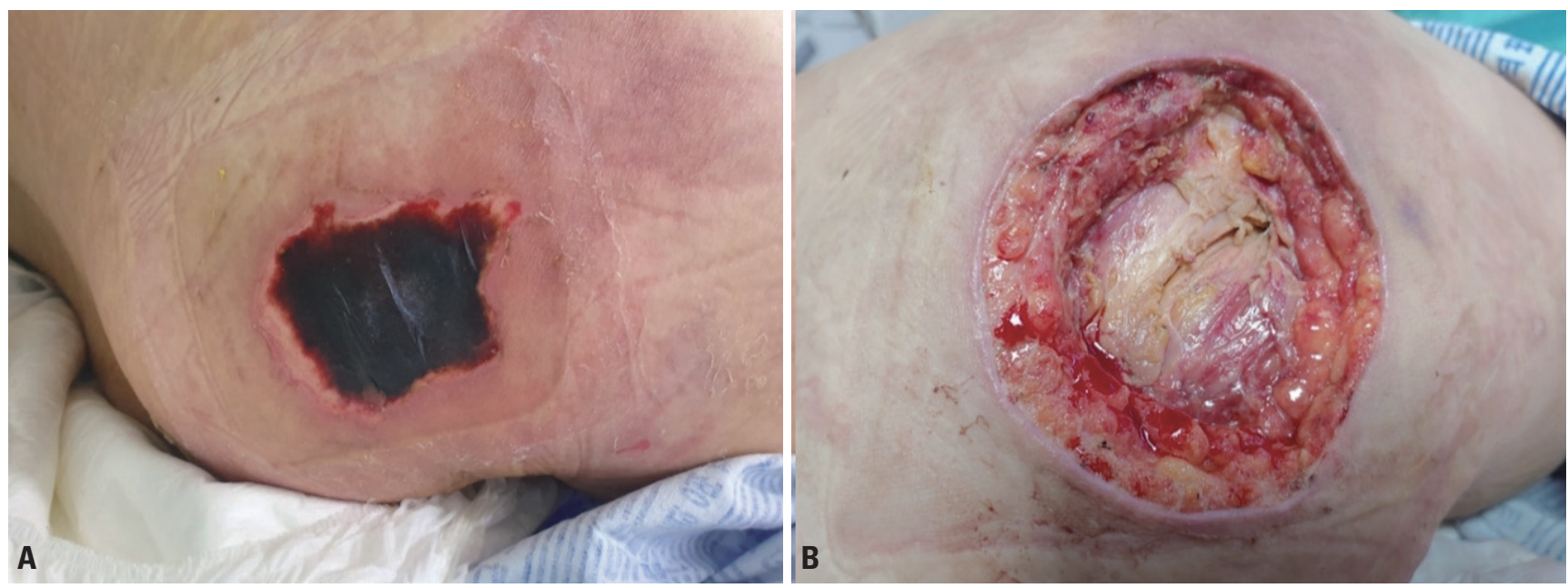

Fig. 1. (A) A grade 3 pressure sore measuring $5 \times 8 \mathrm{~cm}$ was initially observed on the patient's right buttock. (B) After surgical debridement.
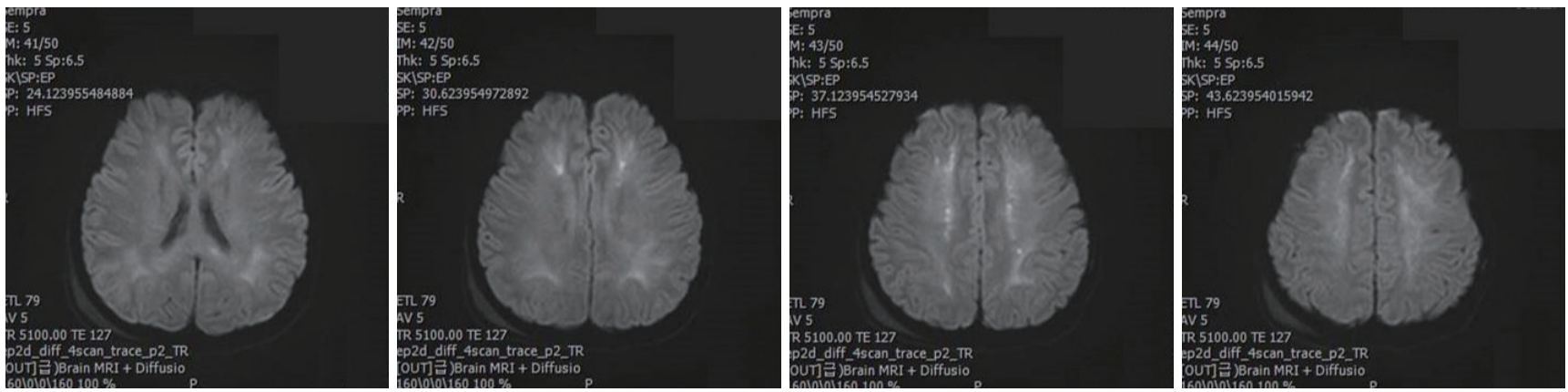

Fig. 2. Brain magnetic resonance images. Acute hypoxic encephalopathy was noted 


\section{JTI}

and the initial $\mathrm{PaCO}_{2}$ was $33 \mathrm{mmHg}$. Her carboxyhemoglobin level was $48 \%$ (reference range: $<0.8 \%$ ). The white blood cell count was $12,310 / \mu \mathrm{L}$, and the platelet count was $115,000 / \mu \mathrm{L}$. The levels of other blood test parameters were as follows: aspartate transaminase, $157 \mathrm{U} / \mathrm{L}$; alanine transaminase, $78 \mathrm{U} / \mathrm{L}$; amylase, $423 \mathrm{U} / \mathrm{L}$ (reference range: 28-100 U/L); lipase, $888 \mathrm{U} / \mathrm{L}$ (reference range: 13-60 U/L); creatine phosphokinase, 3,691 U/L (reference range: 26$174 \mathrm{U} / \mathrm{L}$ ), and troponin $\mathrm{T}, 0.117 \mathrm{ng} / \mathrm{mL}$ (reference range: $<0.1 \mathrm{ng} / \mathrm{mL}$ ). Other laboratory findings were unremarkable. There was no definite lesion on brain CT, but acute ischemic encephalopathy was observed on brain MRI (Fig. 2). HBOT was needed to minimize the possibility of delayed neurological sequelae and to relieve systemic $\mathrm{CO}$ toxicity. However, central catheterization with a 7-Fr catheter had been established in the right subclavian area at the local ED. Iatrogenic pneumothorax at the right upper apex was detected on the chest X-ray and chest
CT images obtained at the local hospital (Figs. 3, 4). The hyperbaric chamber in Dankook University Hospital was a monoplace chamber. Although the pneumothorax was not large, patient monitoring was not possible in the chamber and other medical personnel could not enter the chamber with the patient; therefore, HBOT could not be performed. The patient was admitted to the intensive care unit and surgical debridement of the pressure sore was performed. The pneumothorax resolved spontaneously after several days. She did not regain consciousness, and had a GCS score of 9 on the discharge day.

\section{DISCUSSION}

HBOT is used to provide patients with pure oxygen at higher than atmospheric pressure (2-3 atmospheres absolute), enabling more oxygen to be delivered to the tissue in
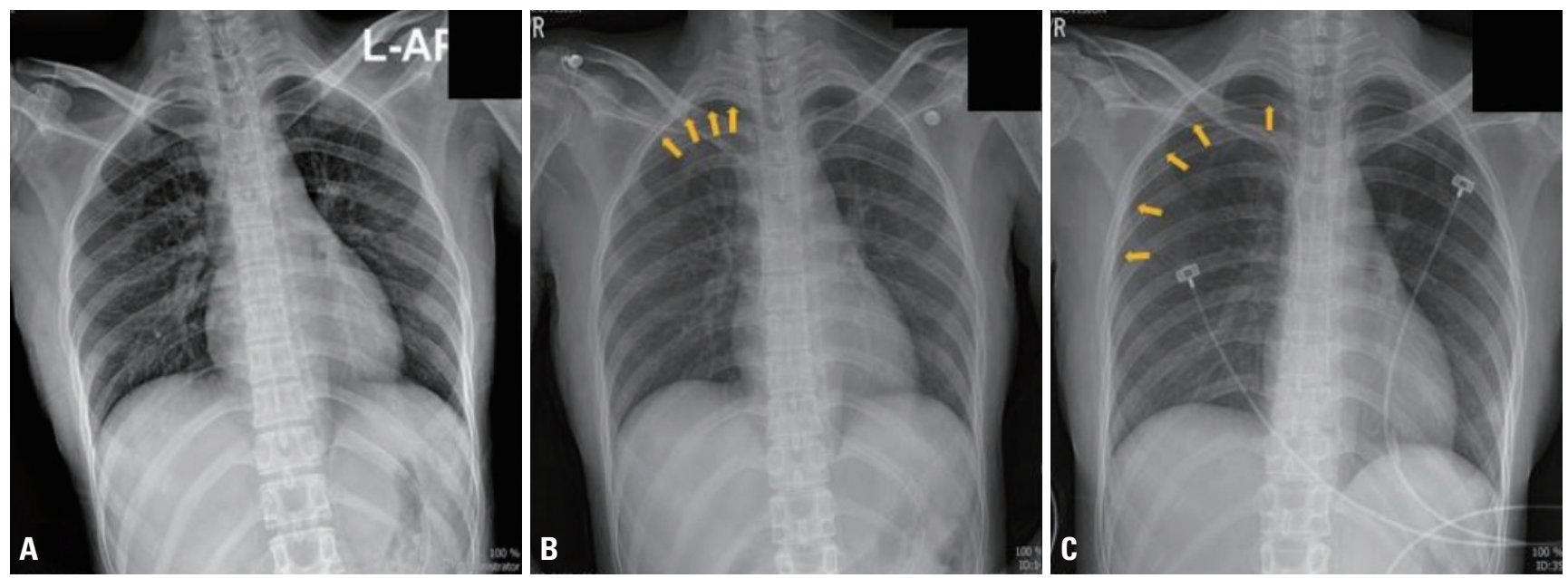

Fig. 3. Chest X-ray images. (A) The initial X-ray before central catheterization. No pneumothorax was noted. (B) An X-ray after central catheterization at the right subclavian area. Pneumothorax was noted. The pleural margin of the lung (arrows). (C) An X-ray obtained on the second hospital day. The amount of the pneumothorax had increased. The pleural margin of the lung (arrows).
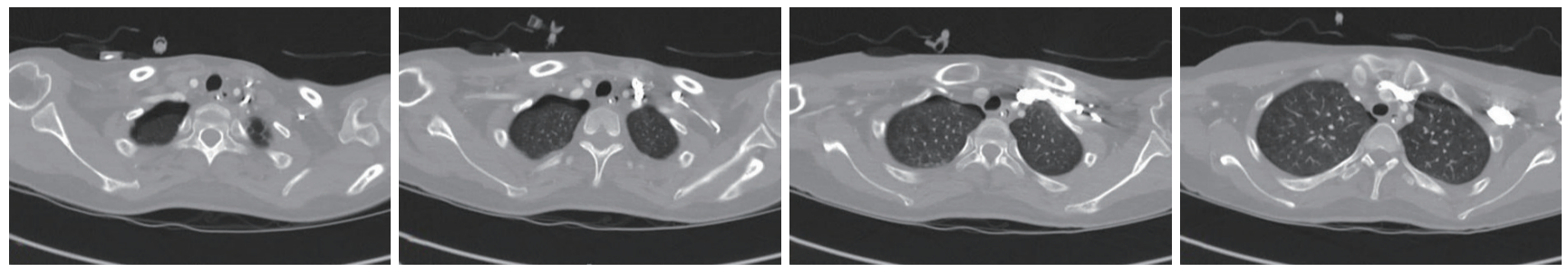

Fig. 4. Chest computed tomography images. Pneumothorax was noted at the right lung apex. 
soluble form in the plasma. Oxygen supplementation lasts for several hours, and the frequency of daily treatment is one to three times a day according to widely used guidelines [1]. To prevent oxygen toxicity, oxygen is usually delivered for 30 minutes and then stopped for 5-10 minutes [2]. HBOT was commonly used as a treatment modality for CO poisoning in Korea in the 1980s. Subsequently, it was used less frequently, as the incidence of $\mathrm{CO}$ poisoning decreased with industrialization. Recently, HBOT has become more common due to the increasing frequency of leisure activities such as camping and the use of $\mathrm{CO}$ poisoning as a suicide method. In Korea, 1,692 patients were treated for CO poisoning in 2014, similar to the number of 1,679 patients treated in 2015; however, this number increased sharply to 3,132 patients in 2016 and 4,338 patients in 2017 [3]. Furthermore, HBOT is gaining popularity as a treatment modality for wound care $[4,5]$. Two types of hyperbaric chambers exist: monoplace chambers, which can be used by one patient, and multiplace chambers, which have room for two or more patients. Only a single patient can enter a monoplace hyperbaric chamber, without accompaniment by medical personnel. Therefore, it is not possible to monitor vital signs, including measurements of electrocardiography and respiration, or to perform life-saving procedures inside the chamber. In contrast, multiplace hyperbaric chambers enable multiple patients, together with medical staff, to enter the chamber simultaneously, making it possible to perform vital sign monitoring and certain procedures. HBOT is used for

Table 1. Accepted indications for hyperbaric oxygen therapy [1]

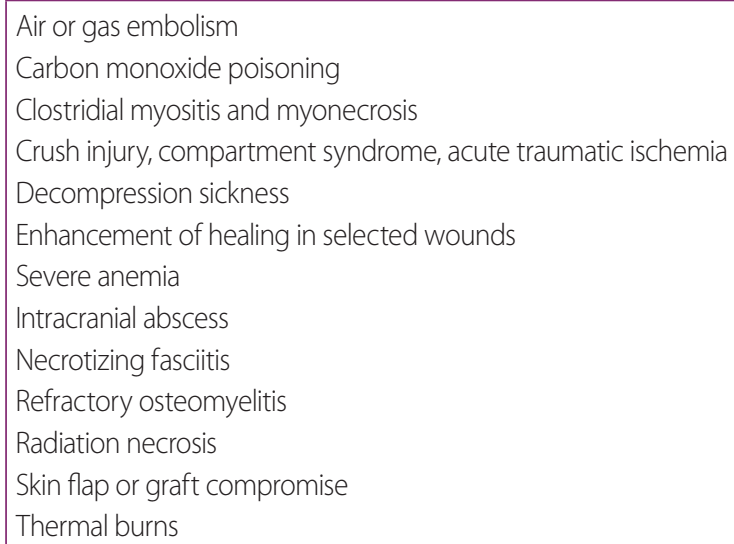

various conditions, including decompression sickness, air embolism, CO poisoning, wound healing, and necrotizing soft tissue infections (Table 1). The only absolute contraindication is untreated pneumothorax. The most significant complication of HBOT is barotrauma, which can cause tension pneumothorax or an air embolism; therefore, caution is needed when treating patients with HBOT [6].

The patient described herein presented acute hypoxic encephalopathy on brain MRI and a pressure sore on her hip, indicating prolonged immobilization. These two findings meant that she needed to be treated with HBOT. However, as only a monoplace hyperbaric chamber was available at Dankook University Hospital, vital signs monitoring was not possible and medical personnel could not enter the chamber with her. We could not predict or observe the development of the patient's tension pneumothorax; therefore, HBOT was not performed, because it was impossible to monitor the patient appropriately. Iatrogenic pneumothorax was confirmed based on the chest X-ray images taken at the local hospital before and after catheterization.

At this point, we must consider why central catheterization was performed. The patient's mental status was depressed, but her vital signs were stable and no vasopressors were infused. A 7-Fr catheter was used, so we can infer that the purpose was not volume hydration-a goal that can be achieved through a peripheral line. Furthermore, when she was transferred to our ED, the only infusate connected to the central catheter was $500 \mathrm{~mL}$ of normal saline.

There are various indications for central catheterization, including the use of hyperalimentation drugs or vasopressors, central venous pressure monitoring, emergency venous access or an inability to obtain peripheral venous access, and hemodialysis. A large catheter can be used for high-volume resuscitation [7]. Central catheterization is a basic procedure for treating critically ill patients and is usually performed in the internal jugular vein, subclavian vein, or femoral vein (the least preferred site due to the risk of infection) [8]. Various complications can occur during catheterization, including air embolism, stroke, pneumothorax, inadvertent arterial or aortic injury, brachial plexus injury, subclavian venous stenosis, infection, 
cardiac tamponade due to perforation, catheter-induced vascular perforation, and diaphragmatic paralysis [9-13]. If a catheter is placed in an artery, it must be removed surgically, not directly [14]. The risk of pneumothorax is higher when approaching at the subclavian site [12]. Although pneumothorax can be simply treated with a chest tube, it does place an additional economic and physical burden on the patient. However, pneumothorax prohibits patients from being treated with HBOT.

The important point in this case is the reason for central catheterization of this patient. The only infused drug was normal saline. This patient was not in hypovolemic shock and did not require rapid volume resuscitation. Moreover, even if she did need to be treated with massive volume resuscitation, much greater flow could be achieved with a peripheral venous catheter, not a 7-Fr central catheter [15]. If the physician had selected internal jugular venous or femoral venous central catheterization (if it was really needed), it would have been possible to treat this patient with HBOT. The referring physician did, in fact, notice the need for HBOT. When we asked the referring physician about the reason for catheterization, he stated that he performed the catheterization because of the possible deterioration of her clinical course. Physicians should consider invasive procedures carefully. Even with the intention of caring for patients, unnecessary invasive treatments can disrupt the course of treatment or impose an additional economic burden. This event could have been prevented if the referring physician had considered-as he should have known to do-the possibility of pneumothorax occurrence with the subclavian approach.

Physicians who perform invasive procedures should consider the following points: first, is it certain that the procedure is necessary? Second, is the equipment (size, site, route, location, etc.) proper for the purpose? Third, if complications develop, what is the next step and are there any concerns regarding the anticipated treatments? Focusing on the successful insertion of the catheter itself without considering these factors is not good judgement or management; instead, it is an obstacle to patient treatment.

\section{REFERENCES}

1. Thom SR. Hyperbaric oxygen in critical care. In: Vincent JL, Abraham EA, Moore FA, Kochanek PM, Fink MP, eds. Textbook of critical care. 6th ed. Philadelphia:Elsevier Saunders;2011:373-5.

2. Leach RM, Rees PJ, Wilmshurst P. Hyperbaric oxygen therapy. BMJ 1998;317:1140-3.

3. Korean Statistical Information Service (KOSIS). The payment status of the inpatients according to the diseases [Internet]. Daejeon: KOSIS 2019 [cited 2019 Nov 26]. Available from: http://kosis.kr/statHtml/statHtml.do?orgId=350\&tblId=DT_35001_A077312\&conn_path=I2.

4. Andrade SM, Santos IC. Hyperbaric oxygen therapy for wound care. Rev Gaucha Enferm 2016;37:e59257.

5. Mathieu D, Marroni A, Kot J. Tenth European Consensus Conference on hyperbaric medicine: recommendations for accepted and non-accepted clinical indications and practice of hyperbaric oxygen treatment. Diving Hyperb Med 2017;47:24-32.

6. Carlson S, Jones J, Brown M, Hess C. Prevention of hyperbaric-associated middle ear barotrauma. Ann Emerg Med 1992;21:1468-71.

7. Christopher R. McNeil SRR, Bruce DA. Central venous catheterization and central venous pressure monitoring. In: Christopher R. McNeil, Salim R. Rezaie, Bruce DA, eds. Roberts and Hedges' clinical procedures in emergency medicine. 6th ed. Philadelphia: Elsevier Saunders; 2014:397-431.

8. Deshpande KS, Hatem C, Ulrich HL, Currie BP, Aldrich TK, Bryan-Brown CW, et al. The incidence of infectious complications of central venous catheters at the subclavian, internal jugular, and femoral sites in an intensive care unit population. Crit Care Med 2005;33:13-20; discussion 234-5.

9. Othman H, Rosman H, Saravolatz L, Rama K. Aortic cannulation: an unexpected complication of central venous catheter placement. J Cardiothorac Vasc Anesth 2017;31:e52-3.

10. Wetzel LR, Patel PR, Pesa NL. Central venous catheter placement in the left internal jugular vein complicated by perforation of the left brachiocephalic vein and massive hemothorax: a case report. A A Case Rep 2017;9:16-9.

11. Yang CW, Bae JS, Park TI, Lee JC, Sohn JE, Kang R, et al. Transient right hemidiaphragmatic paralysis following subclavian venous catheterization: possible implications of anatomical variation of the phrenic nerve -a case report-. Korean J Anesthesiol 2013;65:559-61. 
12. Eisen LA, Narasimhan M, Berger JS, Mayo PH, Rosen MJ, Schneider RF. Mechanical complications of central venous catheters. J Intensive Care Med 2006;21:40-6.

13. Mainland PA, Tam WH, Law B, Ngan Kee W. Stroke following central venous cannulation. Lancet 1997;349:921.

14. Pikwer A, Acosta S, Kölbel T, Malina M, Sonesson B, Akeson J.
Management of inadvertent arterial catheterisation associated with central venous access procedures. Eur J Vasc Endovasc Surg 2009;38:707-14.

15. Marino P. Vascular access. In: Marino P, ed. The ICU book. 4th ed. Philadelphia:Wolters Kluwer;2014:3-15. 